\title{
A learning set procedure involving circular triad problems
}

\section{MYMON GOLDSTEIN AND STANLEY M. FOX, ZECKENDORF CAMPUS, LONG ISLAND UNIVERSITY, Brooklyn, N. Y. 11201}

The idea of circular triads was extracted from its more usual psychometric context and employed as a basis for generating a new learning set task. The task proved difficult for a group of 28 humans.

In connection with a general expansion of learning set technology exemplified by the recent studies of Goldstein \& Wright (1966) and Goldstein \& Easterly (1967), the authors designed a procedure related to the idea of circular triads which occurs from time to time in psychometric work involving the method of comparative judgment. Many aspects of this procedure seem essentially new, and it is our present purpose to acquaint readers with its salient characteristics by describing a one-group experiment on humans and resultant data.

Design. The procedure extended for 108 problems containing three trials apiece, or a total of 324 trials. Each problem required three nonsense forms which were never reused in other problems, so that 324 nonsense forms saw service. Within each problem, every possible pairing of nonsense forms occurred once, as shown schematically in Table 1. Only one of the two possible positional arrangements, $\mathrm{xy}$ or $\mathrm{yx}$, was used for any given pairing of nonsense forms in an overall scheme designed to minimize systematic positional runs of correct alternatives. Designations of correct alternatives were arbitrary on first trials of problems, but were then determined on second and third trials in accordance with the circular triad principle, i.e, each nonsense form was correct exactly once. It was therefore possible to achieve perfect performance on second and third trials by mastering the circular triad principle, but not on first trials.

Procedure. A display was obtained for each trial by pasting printed copies of nonsense forms onto 4 in. $x 6$ in. file cards. The cards were inserted into 14 plastic holders known as "Flip-File" trays that followed each other

Table 1

Schematic Representation of the Experimental Design

Correct

Correct

Problem Trial Display Alternative Problem Trial Display Alternative

\begin{tabular}{|c|c|c|c|c|c|c|c|}
\hline \multirow[t]{3}{*}{1} & 1 & $a b$ & $b$ & 4 & 1 & $\mathrm{jk}$ & $\mathbf{k}$ \\
\hline & 2 & $\mathrm{ca}$ & a & & 2 & $\mathrm{jl}$ & $\mathrm{j}$ \\
\hline & 3 & cb & $\mathrm{c}$ & & 3 & kl & 1 \\
\hline \multirow[t]{3}{*}{2} & 1 & de & d & 5 & 1 & $\mathrm{mn}$ & $\mathrm{m}$ \\
\hline & 2 & $\mathrm{df}$ & $\mathrm{f}$ & & 2 & om & 0 \\
\hline & 3 & ef & $\mathrm{e}$ & & 3 & on & $\mathrm{n}$ \\
\hline \multirow[t]{3}{*}{3} & 1 & gh & $\mathrm{h}$ & 6 & 1 & $p q$ & $\mathrm{p}$ \\
\hline & 2 & in & i & & 2 & $\mathrm{rq}$ & $q$ \\
\hline & 3 & gi & $\mathrm{g}$ & & 3 & $\mathrm{pr}$ & $\mathrm{r}$ \\
\hline
\end{tabular}

Note: There were 108 problems altogether.

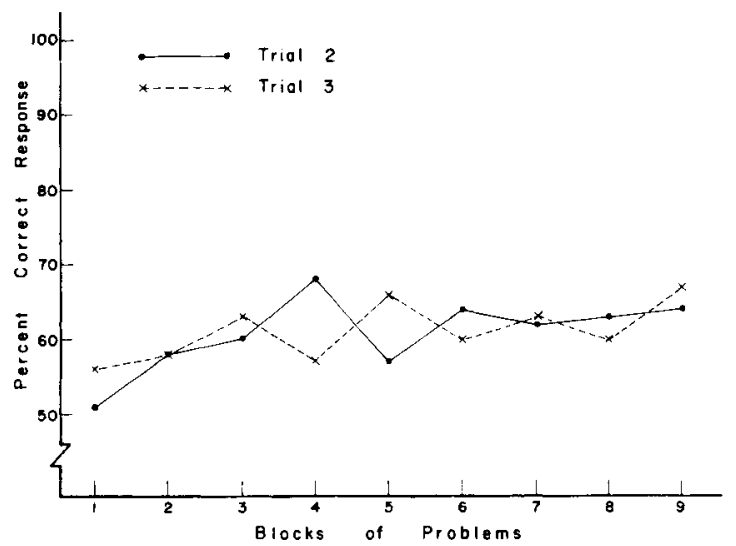

Fig. 1. Learning curves as a function of blocks of problems. There are 12 problems per block.

without delay, $S$ turned the cards and made choices by pointing. E said "correct" or "wrong," recorded response information and assisted in the replacement of trays. The instructions contained only procedural matters and a request that $S$ try to make as many correct choices as possible.

Subjects. The procedure was administered to 28 male and fernale undergraduates, who had been recruited from an introductory psychology class at Long Island University.

Results and Discussion. The data were processed separately for second and third trials, and learning curves across problems were obtained. The curves proved highly erratic, and it was decided to group problems into blocks of 12. A succession of nine such blocks comprised the entire experiment. The two curves obtained this way appear in Fig. 1. These curves exhibit a slight upward trend and no difference between trials. For significance testing purposes, a three-way analysis of variance was run with Ss, trials and blocks as variables and numbers of correct responses as cell entries. The main effects for $S$ s and blocks were significant at better than the .001 level, but all other effects proved insignificant. Several Ss achieved runs of 10 or more consecutive problems correct per trial, but all of them continued to make errors from time to time afterwards. On the whole, the task seems to be extremely difficult for humans. It is not clear how high a level of proficiency can be obtained by adding more problems, because several sessions would then be needed with each $S$ and an elapsed time variable would enter the picture.

\section{REFERENCES}

GOLDSTEIN, M., \& EASTERLY, D. A. Some properties of a three-part learning set task. Psychon. Sci, 1967, 9, 451-452.

GOLDSTEIN, M., \& WRIGHT, P. D. An uncomplicated but difficult two-part learning set task. Psychon. Sci, 1966, 6, 479-480. 